\title{
The use of Socrative in university social science teaching
}

\author{
Sam Pryke
}

\begin{abstract}
Socrative is an online platform that allows a teacher to put questions to students through an app on their smart phone or tablet. In existence since 2011, its use is now quite common in university teaching. But is Socrative any good? This article reviews the literature on the device and discusses my research on the use of the app, the first carried out with social science students. The secondary research findings are that students find Socrative easy to use, fun, of genuine benefit to their learning and a medium that aids active participation. Furthermore, there is evidence that it benefits attainment as testing helps memory retention. My research findings broadly concur. Also considered is how Socrative use can be extended beyond revision-style testing to introduce students to new information that challenges existing beliefs and to elicit controversial opinions and sensitive information.
\end{abstract}

\section{KEYWORDS}

active learning, lectures, memory, participation, Socrative, testing

Socrative is a free, online, therefore real-time, Web platform for teachers to put questions to students through an app on their smartphone or tablet device. Since its launch in 2011, it has become widely used and is now the market leader of its type. It is likely that its predominant use is in high schools in the United States, but it is now a fairly common aid in university level teaching internationally. But is Socrative effective? In as much as Socrative simply provides the teacher with a new, twenty-first century means of the age-old teaching technique - as old as education itself - of putting questions to students, there clearly is no case to answer. However, the varied forms of questioning Socrative allows prompts investigation into this teaching tool. This article attempts to address some of the issues thrown up by its advent, perhaps issues teachers have not always paused to consider as they 
have embraced something that is fun and allows them to direct students in the use of their mobile phones in the lecture theatre, seminar or workshop.

The article is organised into four sections. First, I briefly describe how Socrative works and indicate the success of the app. Second, I draw together the findings of a number of articles on Socrative use in higher education that have been published in teaching and learning journals over the last seven years, in itself a reflection of the popularity of the Web-based platform. In doing so, I also make some reference to the psychological study of the relationship between testing and memory retention. Third, I present findings from the research I carried out amongst second- and third-year Sociology students at a British university, the first survey amongst social science students in a UK higher education institution that I am aware of - or indeed anywhere else. Finally, I indicate, with examples, the varied forms of questions to which Socrative lends itself.

\section{The use and success of Socrative}

Typically, a teacher using Socrative will bring up a test in Socrative Teacher on the teaching room PC/screen, students will note the 'room' they must enter to access the test on their Socrative Student app (they do not need an account) and then they will proceed to answer the questions. The teacher can decide to use Socrative for a 'Quick Question' within a lecture or pose several questions in a test at the end. The question format can be either multiple choice or closed (true/false). Photographs can be added beside the question and there is a box for text explanation to accompany the identified correct answer. Through the 'delivery mode and settings', the teacher can decide whether the test is student or teacher paced and, should the former option be chosen, whether the answers (and explanation if entered) are revealed instantly, upon completion or not at all - as in a 'proper' test or exam. Furthermore, the teacher can set whether the correct answer to the given questions are displayed on the app they are using, or only shown on the screen at the front of the teaching room. The question posed can be individual or group. A question directed to a specified group is termed a 'Space Race' in Socrative speak. Finally, the teacher can decide whether the class results are anonymous or named. Socrative also allows for students to text questions or other responses to their teacher through a 'back channel' function. A record of the overall results of a test can be displayed on the class screen and/or saved to an Excel form for future reference. In my experience, 
an academic who has some general level of IT (information technology) experience and competence, but certainly would not class themselves as IT proficient, can get to grips with Socrative in an hour. Its simplicity of use, together with its attractive and uncluttered interface, are undoubtedly key reasons for the popularity of Socrative, the market leader in this area of educational technology.

Certainly, Socrative has been successful, although it is probably not an academic household name. It was launched by Cambridge Massachusetts Software in 2011 and bought by MasteryConnect of Salt Lake City, Utah, in 2014 for $\$ 5$ million. After several years of free use, a commercial version, SocrativePro, with enhanced features was created in 2016. At the time of this fee-paying innovation, the company (Business Wire 2016) claimed that Socrative had users in sixty-five countries, was offered in fourteen languages and was 'already used by over 16 million educators and students worldwide'. In addition, there is now a Socrative Pro for Higher Ed at $\$ 99.99$ annually. This is the only version that can be used for an audience of more than fifty people. As the principal attribute of Socrative is its facility to convey questions to a large audience, this commercial aspect clearly represents a restriction on its use, especially in developing countries, although it is of course predictable. However, Socrative continues to grow in terms of teaching accounts. The current figure for teacher accounts is nearly 3 million according to the company.

\section{Research on Socrative: Questioning the questioning device}

The typical background to a publication on Socrative is that an academic hears of it as a smartphone alternative to a hand-held SRS (student response system) clicker device, uses it on a module or two and then, using an online survey tool, researches what their students thought of it. Some authors (Rae and O'Malley 2017) say that they carried out research with a view to extending and widening its use; others (Lim 2017) simply seemed to have been interested in their students' views. In any event, over the last seven years there have been investigations of Socrative use at universities in a number of countries: trainee teachers in Turkey (Aslan and Seker 2016), IT students in Malaysia (Lim 2017), architecture undergrads in Saudi Arabia (Awedh et al. 2014), Spanish engineers (Badia et al. 2016) and physics students (Méndez and Slisko 2013), Croatian electronics undergraduates (Tretinjak et al. 2015), Irish medics (Rae and O'Malley 2017) and sports management students (Dervan 2014), and pharmacy majors in the United States (Guarascio et al. 2017). 
Some of the authors place their research in a pedagogic context. For instance, Guarascio, Nemecek, and Zimmerman (2017: 809) evaluate Socrative in relation to 'traditional students' response systems', that is, a teacher asking questions to a class and students raising their hands to answer. Dervan (2014: 1803) examines its use as an alternative to hand-held clickers. In both instances, the comparisons were positive: Socrative is better; it constitutes progress. Dervan also says that the device is an aspect of active learning, defined broadly as any activity that engages students in the learning process by requiring them 'to do meaningful activities and think about what they are doing' (2014: 1804). Others (Rae and O’Malley 2017; Nouri 2016: 4) refer to the use of Socrative as part of an attempt to foster a 'flipped classroom': a forum in which students participate in learning exercises based on reading, videos, etc. they have studied through a virtual learning environment prior to attending the contact session with the teacher. It is worth noting that such was Rae and O’Malley's (2017) scepticism of the flipped classroom approach actually succeeding, that is, the students routinely doing the expected preparation, that they elected to conduct Socrative quizzes after lectures on content just covered, rather than at the start of teaching sessions on material students had been supposed to study beforehand. They had found that their students, medical students at that, who did not carry out the learning tasks were generally absent from classes.

There is perhaps another reason for the use of and interest in Socrative, one not mentioned in the literature. It is well known that teachers generally dislike their students staring at their smartphones rather than looking at them and paying attention. There is the justification that they may be Googling definitions and so on, but one senses that the resigned teacher only half believes this. Socrative then surely has some aspect of 'If you can't beat them, join them!' It entails the teacher directing use of smartphones in an age-old activity: asking students questions. Moreover, it tests students' attention over the course of a lecture, a period when there has been inevitable concentration loss - not least from checking incoming social media messages on smart phones.

Few of the authors (Dervan 2014 is an exception) comment on the issue of smartphone ownership, an obvious prerequisite for Socrative access. The assumption, one that corresponds to my own experience, seems to be that 
the number of students who do not have smartphones is now negligible. This is not Western conceit: several of the studies were carried out in middleincome countries. There is some mention of technical issues. As an online platform, ease of Socrative use is relative to the quality of the Wi-Fi in operation. As one might expect, reported practical problems vary in the studies conducted from noteworthy (Aslan and Seker 2016: 170) to non-existent (Guarascio et al. 2017). There are no mentions of complete malfunctions of the programme or app.

These things are undoubtedly important to high student satisfaction levels with Socrative. Of those studies that asked participants directly if they liked using Socrative, the responses ranged from 82 per cent (Tretinjak et al. 2015: 850) to 95.3 per cent (Rae and O'Malley 2017). Lim (2017: 410) notes a general satisfaction level with Socrative amongst students of 84 per cent. On the related question as to whether Socrative aided participation, Aslan and Seker (2016: 169) found that 100 per cent of their students thought that it did, whilst Rae and O'Malley (2017) give a figure of 92.2 per cent. Highly positive ratings have been found for similar questions. In the study by Awedh et al. (2014: 22), 84 per cent of students thought that it had it aided 'active collaboration in my learning experience', Badia, Cazevieille and Jover (2016: 85) found that ' $85 \%$ [of their students] felt that the tool is interesting, because it gets them involved throughout the entire activity, while only $4 \%$ disagreed with this statement'. An interesting finding of the most recent publication on Socrative, based on research with first-year physics students in Turkey (Balta and Tzafilkou 2019), is that the popularity of Socrative is directly related to the difficulty of subject matter. They found that the initial enthusiasm of undergraduates waned as they struggled with the content of the tests and their grades fell. The authors comment, 'As time passed by, the difficulty of physics surpasses the glamorousness of Socrative'. However, this qualification should not detract from the wider observation that students like Socrative.

Beyond general endorsements, the studies also indicate that students think that they have benefitted from Socrative use. Responses to more specific questions indicate that students think it has helped them learn and retain new information. The study by Dervan (2014: 1808) delved deeper into the general finding that 92 per cent of students considered Socrative an aid to learning, to reveal that 88 per cent thought that it highlighted gaps in their knowledge, 63 per cent thought that it helped the lecturer understand where the students had difficulties in their learning (this does not seem to 
have been through the backchannel function) and 96 per cent thought that it had introduced some fun into lectures. Badia, Cazevielle and Jover (2016: 86) found that 81 per cent of their respondents thought that 'it contributes to integrating new knowledge'. Similarly, positive results in the survey conducted by Rae and O'Malley (2017) prompt them to claim that students did not consider Socrative use as 'a simple "gimmick" employed by the lecturer for their amusement', but of genuine educational benefit.

Several of the studies asked for comments on Socrative besides compiling quantifiable responses. In the study by Rae and O'Malley (2017), these show that students think that Socrative aids their attainment through its instant test aspect. One commented, 'Learning from examples (e.g. questions) is one of the ways that I am able to retain the information that has been taught. I perform better if I've had some experience answering questions rather than just listening to a lecture'. Others (Dervan 2014: 1808) say that the anonymous aspect of Socrative allows a teacher to engage quieter students who never spoke up in class. This point is in relation to questions put to students by a teacher. As indicated, Socrative also allows the converse through its backchannel function. On this Guarascio, Nemecek and Zimmerman (2017: 4) state, 'Students felt that Socrative helped them to participate in class more effectively and facilitated answers to classroom questions, while creating a "safer" environment for students to anonymously ask questions in class compared to the hand raising method'.

So, there is definite evidence that students like Socrative and think it is a genuine aid to their learning. However, it is important to note that the existing studies are not entirely positive. An obvious point about Socrative, noted in only one article (Tretinjak et al. 2015: 848), is that preparing tests is time consuming - quite possibly highly time consuming. If a teacher is to use it routinely (probably weekly, certainly fortnightly) as an integral aspect of a course, as opposed to an occasional novelty, he or she will have to undertake hours of additional preparation. Obviously if the course is to be repeated, the tests will be there in years to come and can be updated with minimal trouble, but the initial time invested can be considerable. A possible pedagogic issue is that the repetitive use of Socrative may become less 'test like', thus reducing its memory enhancing potential (see below). A point that Dervan (2014: 1805) makes is that it is important the teacher has a thought-out strategy in relation to Socrative use(s). If this is lacking, some students will come to see Socrative as a hollow activity, a time filler and/or tech novelty that quickly loses its appeal, rather than a genuine teaching aid. The judicious 
use of Socrative is something that I consider in the final section of this article. Related to this, there is some evidence that students think there are definite limits to constructive Socrative use. As noted above, Aslan and Seker (2016: 170) found that whilst their students were overwhelmingly positive about Socrative, only 20.8 per cent of those surveyed said that they would want it to be used more than fortnightly in teaching sessions.

The evidence that Socrative enhances student attainment is less certain. Dervan (2014: 1804) states that there is such evidence, but the studies he cites looked at the use of clickers as SRS, rather than Socrative as such. The only author who finds that Socrative enhances attainment is Lim (2017: 410). He seems to have come to use Socrative both within teaching sessions and for assessed tests - both as a formative and summative learning tool. He says that the improvement was definite: 'Students performance in quizzes and exams were significantly improved upon the implementation of Socrative from $66.76 \%$ in 2015 to $72.4 \%$ in 2016 , and from $46.48 \%$ in 2015 to $59.45 \%$ in 2016'. However, he notes that there was no knock-on improvement in group work scores (where different skill sets are required) or improvement in attendance.

On the relationship between memory retention and tests there is definite evidence. One much referenced, seemingly authoritative, study by Roediger and Karpicke (2006) found that in various comparative studies they organised, subjecting participants to a test shortly after exposure to information (a short passage participants read) enhanced their longer-term recall of the given content. This was true and the difference was significant for tested participants even when compared to those who had read the passage twice. According to Roediger and Karpicke (2006: 252) participants who read the given passage more than once felt more confident that they had retained the information, but the researchers found that this was clearly not the case in the longer term. If a test was carried out, if participants undertook the mental task of drawing upon the content they had recently tried to absorb, they were more likely to remember the subject matter accurately over a longer time period. The ability to remember the details of a prose passage in a free-recall test a week or more after learning is enhanced by practicing exactly this skill immediately afterwards. The authors (2006: 254) conclude, 'Practicing the skills during learning that are needed during retrieval generally enhances retention on both explicit and implicit memory tests'. Now one might quibble that Socrative is not generally being used in higher education for 'proper tests', but for fun quizzes. However, the point stands that use of the learning 
technique intrinsic to Socrative, conveying and/or reiterating information through questions and answers rather than simply transferring information through statements, is in itself likely to cement memory.

This finding is consistent with psychological research on how testing can be interpolated (blended) with information conveyed in a traditional university lecture. Szpunar, Novall and Schacter (2013) examined how tests - in what form exactly and when conducted is not indicated - both enhance concentration and improve attainment. They say of their research, 'The present results demonstrate that interpolating an online lecture with testing can help students to quickly and efficiently extract lecture content by reducing the occurrence of mind wandering, increasing the frequency of note taking, and facilitating learning' (Szpunar et al. 2013: 6316). As to why this is the case exactly, Szpunar, Novall and Schacter (2013) suggest that the inherently demanding and competitive format of a test is likely to produce some emotional stress. This may not be a desirable goal in itself, but there is definite evidence (Levine and Edelstein 2009) that emotion enhances memory retention over longer periods of time. As noted above, there is a possible corollary here that breaking up a teaching session into a variety of segments may in itself undermine concentration as the time span becomes fragmented. However, the evidence suggests that the memory-enhancing role of testing outweighs this risk.

\section{My research on Socrative}

I first came across Socrative in the first semester of the academic year 2015-16 when it was suggested to me as a smart phone quiz alternative to a clicker device I had used for several years. Having trialled it several times in the first semester and found that it was easy to operate and seemingly popular with students, I used it more extensively in the second semester. Specifically, I used Socrative in that period (and subsequently) with two groups of students: a compulsory second year classical social theory module and a third-year option on migration. Since then, I have also used Socrative on an introductory first year module and a third-year globalisation class. The students were taking either single honours Sociology or Sociology combined with another subject (typically Criminology) at a post-1992 British university. Teaching on the modules was in three-hour blocks: a two-hour lecture (with breaks!) in which I used Socrative and an hour-long seminar. The survey I carried out at the end of the semester with second-year (social theory) and 
third-year (sociology of migration) students contained both quantitative and qualitative questions. It was administered through Online Survey. I used SPSS (Statistical Package for the Social Sciences) software to produce the simple pie charts below. It was primarily designed to hone my subsequent use of the device as I was conscious at the time of something mentioned above: it is important to have a thought-out strategy vis-à-vis Socrative use, lest it becomes a superficial time-filler.

The combined response to my questionnaire was relatively high: fiftythree of sixty-seven students. The findings are represented by the pie charts in Tables 1, 2 and 3.

In view of the issue raised above of the degree to which Socrative is more than a fun time-filler, the second chart (Table 2) is revealing. Some 84 per cent believed it something that genuinely added to the module and contributed to their knowledge of the subject.

Table 3 indicates that 74 per cent, a substantial majority, but not an overwhelming number, said that they would have liked greater use of Socrative in other modules on their degree.

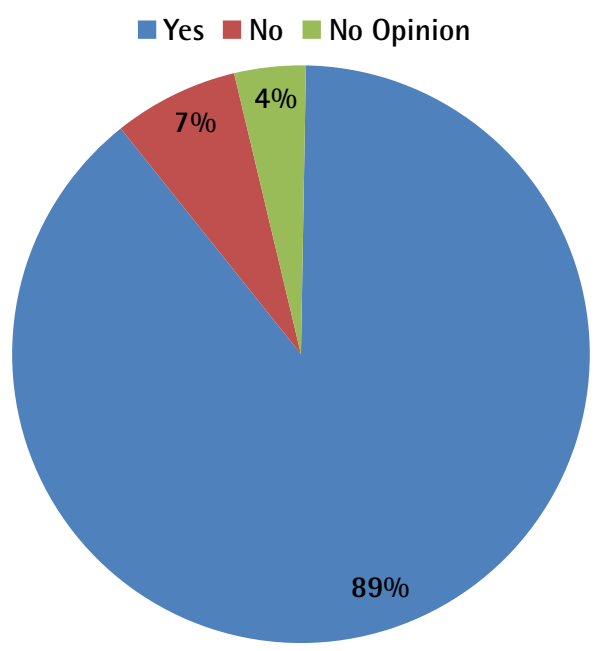

Table 1. Answers to the question 'In general terms, do you think Socrative added something to lectures?' 


\section{A little Light Relief $\square$ A Genuinely Useful Tool}

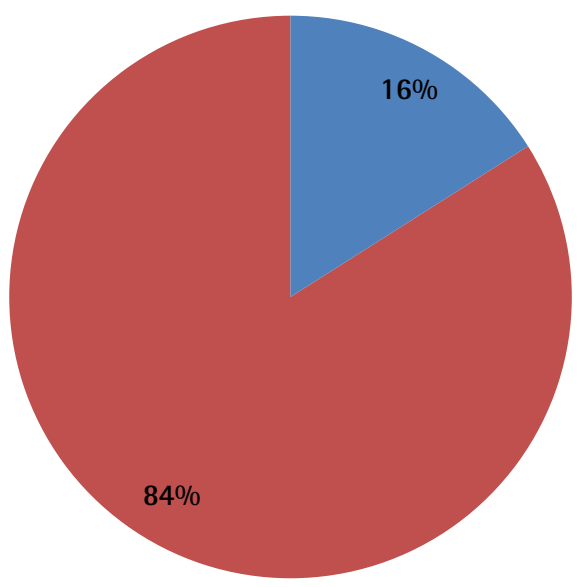

Table 2. Answers to the question "If you answered "Yes", did you do so because you thought it was just a little light relief from lectures or was it something that genuinely added to the module and contributed to your knowledge of the subject?'

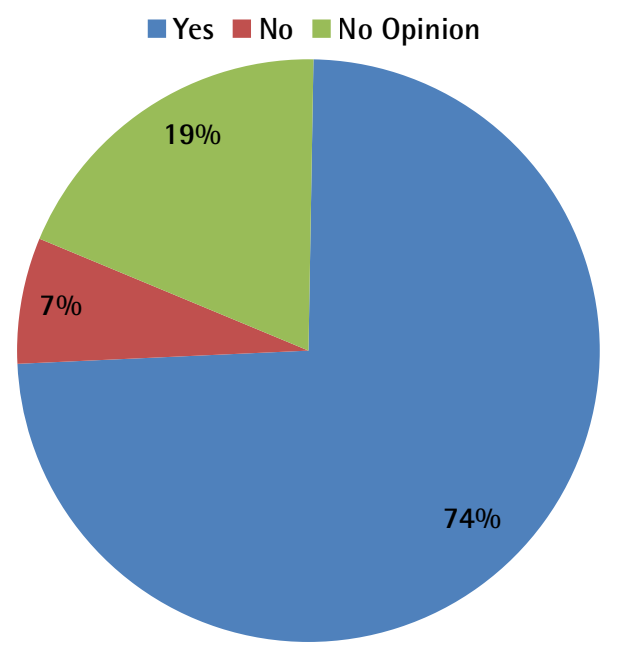

Table 3. Answers to the question 'Would you like greater use of Socrative in other modules on your degree?' 
Taken together, the responses were broadly in line with the findings referred to in the last section: Socrative is popular, most students think it aided their learning, whilst the number of students who favour greater use is high but not overwhelming.

More interesting were the qualitative responses I received. This was through a box I left at the end of the survey for any further thoughts about Socrative. In hindsight (there was no pilot survey), it would have been a good idea to have asked directed questions, though this may have negatively affected the response rate. In any event, I received enough varied answers to identify various themes that have since informed my use of Socrative.

The first was that student comments reiterated the 'fun but more than fun' finding of question two. One student commented on the 'healthy competition' generated 'amongst students who can test their knowledge against each other'. Another felt that they would have liked use of the Socrative leader board option to display names and scores. On several occasions, rather than displaying names on the class screen I asked students who scored ten out of ten on the quiz, who scored 9, and so on and given a little prize (old DVDs) to the winner(s) - sometimes several students. Another related point is that several students thought that Socrative is a constructive relief from lectures. One commented, 'I thought that it was useful at times when earlier lectures were particularly intensive, because it meant that by using Socrative we could relax a little'. Another said, 'I think the use of Socrative was great as it allowed a ten-minute breather from a long lecture, and at the same time still challenged our memories on the subject area'.

A second theme was the revision aid - the most obvious and, judging from the research, the most common use of Socrative. On this a student remarked, 'I think it was really good, it gave everyone a chance to revise the last session and answer without having to interact and answer in front of the whole class'. Another wrote, 'It was good because it was sort of like a little test of what we had learned'. Students who gave opinions on when Socrative should be used in a teaching session pointed to the revision benefit: 'Good as a revision tool/pop quiz style game to cover things we had learnt in lectures, either on that same day or the week later as a reminder or catch up'. Several others thought that it should have been a more systematic aspect of the module, that is, every session should start with a recap of the content of the week before through a Socrative test. Related to this, is the assurance Socrative instilled. One commented that Socrative 'gave me confidence as it showed me how much I actually knew!' 
There are two comments I would make on this finding of Socrative as a revision aid. One is that there was no opportunity on the modules for students to formally benefit from the memory enhancement they perceived. That was because both assessments on the two modules were through coursework, rather than through a final examination. Nevertheless, insofar as education is about the benefits to the individual of lasting knowledge and understanding, rather than academic attainment, it is likely to have had this effect. The second is that the point about self-confidence is worth reiterating. Students at post-1992 universities, especially those within the first generation of their families to enter university, often make their way through their degrees by diligently working on successive assignments whilst suffering from an ongoing lack of belief in their intellectual abilities. The boost given to self-esteem by doing well on a Socrative test may be relatively minor, but as a demonstration of their own intelligence it should not be dismissed.

A third theme from the student comments, one noted in the literature above, is that Socrative is a stimulus to class interaction. Whilst in this period of its use in my teaching sessions, I put questions to individuals rather than groups, there were a number of occasions when some discussion followed a question and answer. One student observed that Socrative allowed her/him to 'interact with one another as well as their tutor'. Another thought that Socrative can encourage debates and that 'lectures are more interesting in my opinion when students can participate in meaningful debates'. He/she added that it encourages 'shy students to participate in lectures if only through their smartphone'.

\section{Socrative in social science teaching - beyond testing}

Some of the articles (for example Rae and O'Malley 2017) mentioned earlier refer to the timing of their Socrative tests. However, the question format of Socrative has not been addressed. In the next section of the article, I outline the types of questions I have put to students through Socrative.

Like others who attended university in the 1980s and then came into higher education teaching in the 1990s, I initially relied on the traditional format of lecture and seminar and would, perhaps, once have thought a class quiz as contrary to the scholarly character of the university. However, as the years have gone by, I have become more open to innovation. Moreover, Socrative does not depart from traditional conceptions of learning. On one level, all it does is to reformat how a teacher questions students. Moreover, 
the question forms are not dependent on Socrative as they could be put in other ways. But the examples below do demonstrate that the app can be deployed in varied and creative ways to encourage speculation and elicit opinion, as well as retain information. As indicated above, I have found that it is rare that students do not have a smartphone. Generally, I have printed a few paper copies of the quiz in case there is this issue. On one occasion when I had not done this, I can recall asking a student to simply note her answers on a piece of paper as the questions were displayed on the board.

The first and most obvious way to use Socrative is for a revision of material covered in a lecture. A question might be simply factual, like the year of publication of a key book, or more conceptual, like the best definition of a term. I give two such examples in Figures 1 and 2. The correct answer is revealed through green colouration on clicking on 'How'd we do?' (Figure 3) if the test is run with the instant feedback option turned on. There is, of course, the issue that the answer may well be there on the PowerPoint (or other presentation means) used for the lecture, made available through the module VLE (Virtual Learning Environment). Alternatively, students could

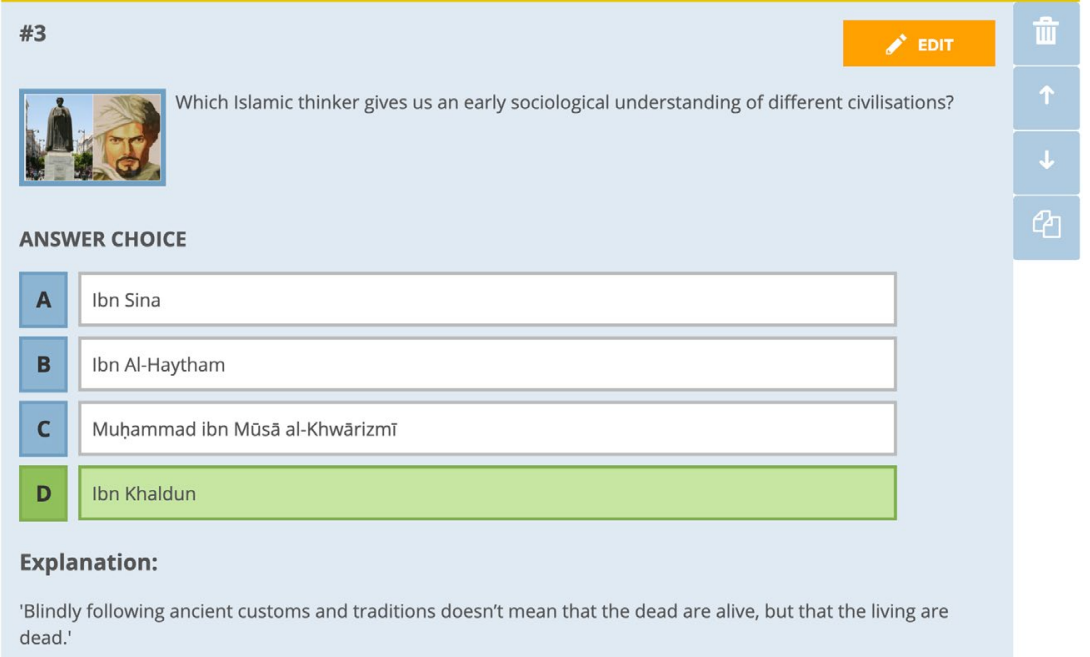

Figure 1. Factual recapitulation 


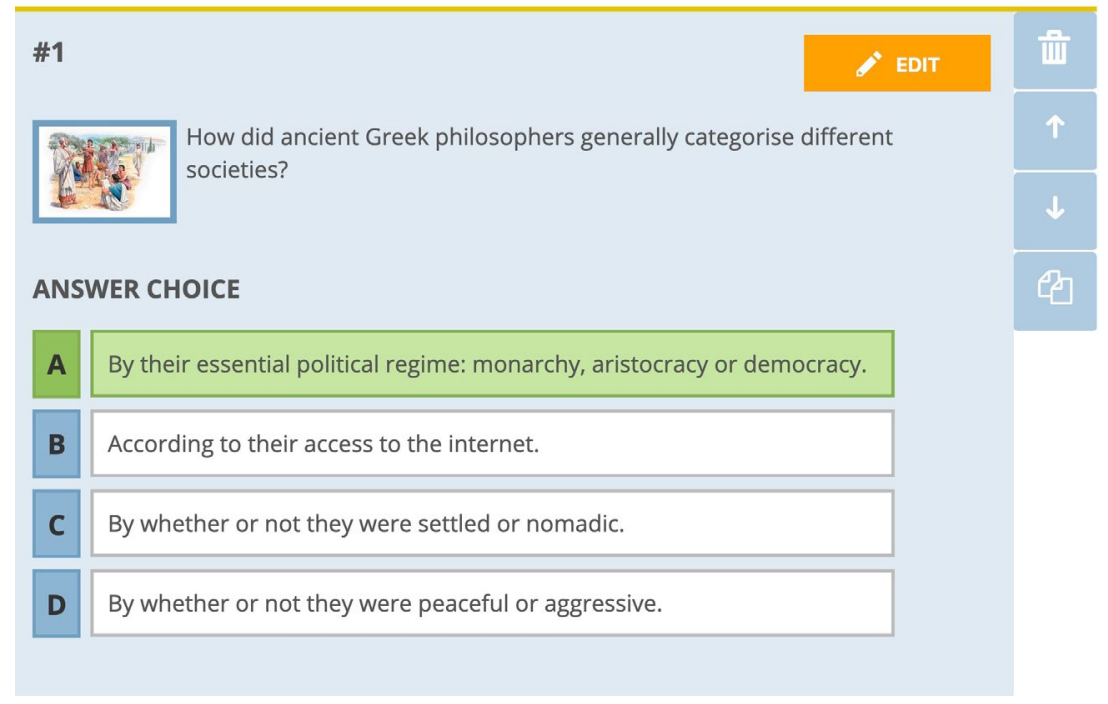

Figure 2. Factual recapitulation

google the answer. My experience here is that if it is pointed out to students that the test is only to help their learning and does not count towards their assessment mark, they do not cheat. As to the timing of Socrative use, my instinct was that it was better to test material at the start of the session the following week, as it seemed too easy to test material just covered. However, student scores were generally significantly higher on tests at the end of lectures (or in the seminar immediately following). Moreover, as noted above, testing in itself is likely to instil memory, so I have generally come to use it immediately or shortly after lectures.

The second way I have used Socrative is to convey information that is noteworthy or even surprising, but if simply stated in a lecture would appear mundane. Therefore, the question form in itself makes the information significant and perhaps memorable. The example in Figure 3 is from a first-year lecture. Rather than reel off some statistics on marriage and divorce at a given point within the lecture, I put the information through Socrative to groups of three or four students. Of course, the students only guessed at the answers but I noted that some constructive, if ad hoc, debate did take place on what was likely to be the correct choice. Some further discussion took place when I subsequently asked aloud about possible reasons for the fall 


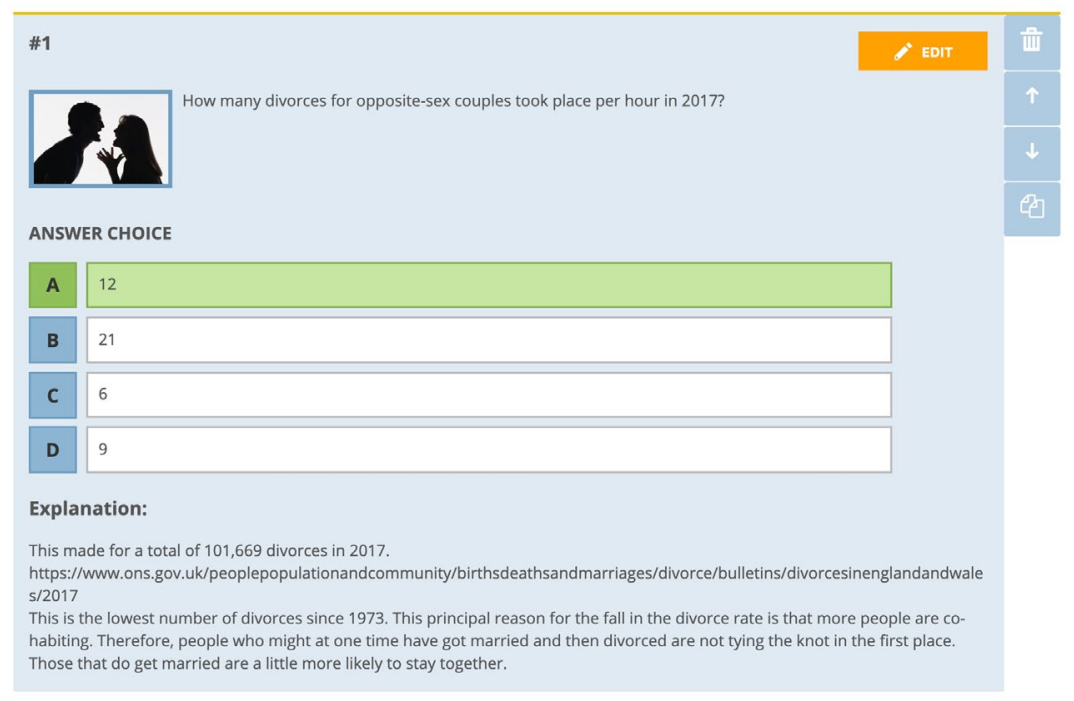

Figure 3. Noteworthy information

in divorce in recent years, before I confirmed the principal cause (the rise in co-habitation) through the explanation box at the bottom. Moreover, it was perhaps more likely that some followed up on the source of the information, from the Office for National Statistics website, than would otherwise have been the case if I had simply mentioned the agency in the lecture and listed it in the PowerPoint bibliography.

My third use of Socrative has been to introduce information that may question pre-conceived notions - part of the wider intellectual task of sociology of challenging common sense. In my third-year option, I have included a test in the first session on world, European and British migration levels. In response to the first question below, Figure 4, most students opted for higher numbers on the percentage of the world's population who are classed as migrants (living in a country other than the one in which they were born) than the correct answer: D 3.2 per cent. The obvious point to make following revelation of the answer through 'How'd we do?', is that whilst the number has gone up, it is still relatively small in global terms - a point that stands even if this figure is an underestimate given undocumented migration. The subsequent academic point, that migration is in total terms surprisingly low, not high, is perhaps more likely to stick if conveyed in such a form. 


\section{Sam Pryke}

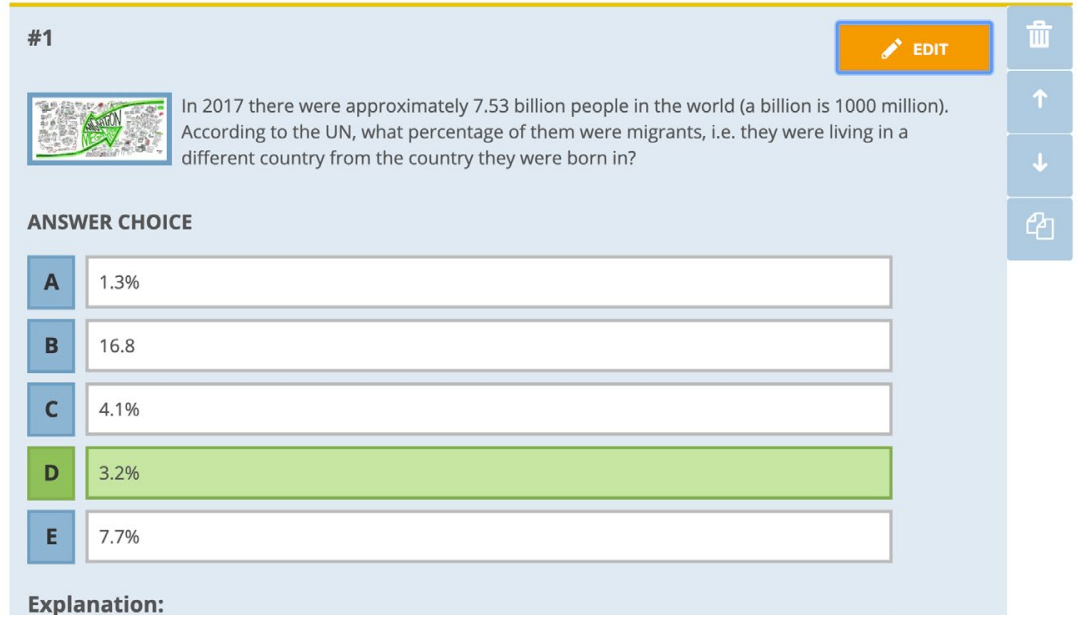

Figure 4. Noteworthy information

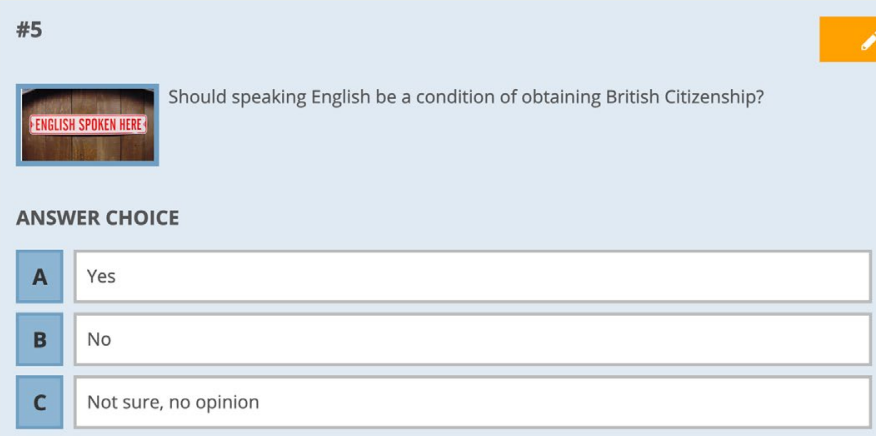

Figure 5. Controversial anonymous opinion

I have also used Socrative to gauge opinions about migration, specifically immigration, in the latter part of the same opening session quiz. Whilst attitudes of Sociology undergraduates to immigrants and immigration are not especially liberal, students are generally concerned not to appear intolerant. With the answers compiled anonymously and displayed to a question like that in Figure 5, some worthwhile class discussion on the question of citizenship and language proficiency did then take place. 


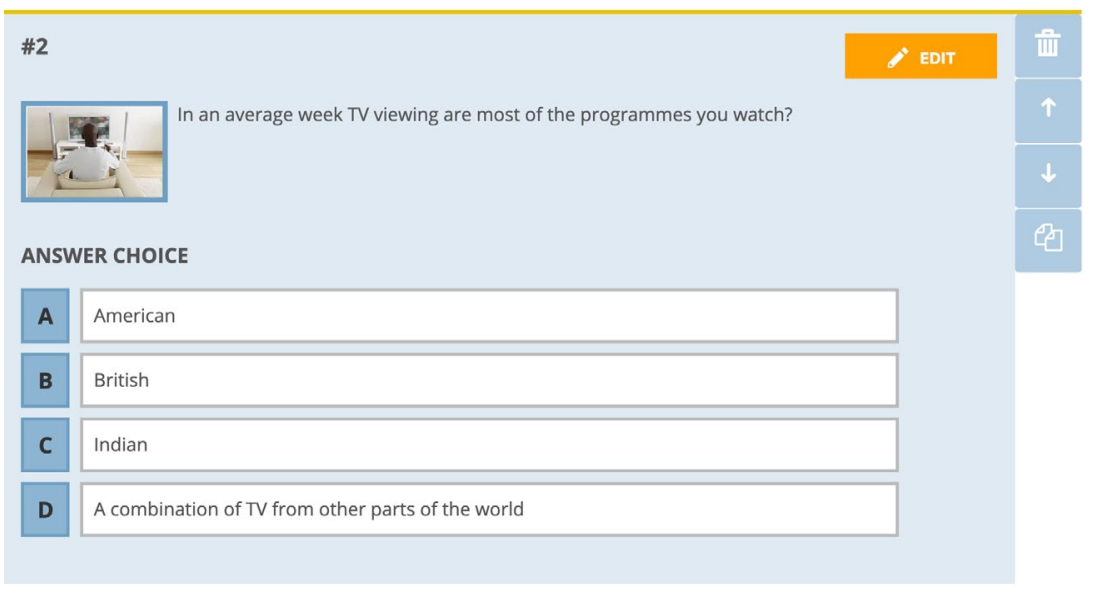

Figure 6. Surveying the students

I have not used Socrative to elicit personal or otherwise sensitive information, but with appropriate preparation involving permission, it could conceivably be used in sociology (or psychology) teaching. For example, in a criminology class, it might - with adequate warning, assurances of anonymity and details of organisations offering counselling and advice - be used to draw out experiences of various types of crime.

Finally, I have used Socrative to acquire information that is itself sociologically interesting, for example, to conduct a mini survey. In the session on global culture in the module mentioned above, I used the question below (figure 6) for an indication of the students' weekly TV viewing.

In a similar fashion, I have also used Socrative to ask about types of social media use. With groups of students who have been seen to be especially keen on Socrative, I have been motivated to put the work into preparing as many as eight quizzes in a single semester. More often, I have used it three or four times over a single module to recap information conveyed. 


\section{Conclusion}

Socrative is a Web-based device that allows a teacher to put questions to students through a free app that they have downloaded onto their smart phones or tablets. Its use in higher education teaching is now quite common. It is likely that many of those who initially used it had previously put questions to students through hand-held clickers. As is the way in the spread of IT, they no doubt recommended it to others as a new, easy-to-use smartphone device. And so Socrative's number of users has expanded - and in all probability is likely to further do so, even though its free use is now limited to fifty users or fewer. The success of Socrative has generated educational research over the last seven years, resulting in the publication of a number of articles. The articles find that students like Socrative and think that it has encouraged their participation (active learning) in lectures - a form of teaching that, for all the familiar criticisms, is still widely used in universities. Moreover, there is some evidence that Socrative tests improve student academic performance. The likely reason is that testing helps longer term memory retention. The optimal time for testing is shortly after exposure to information. Thus, the best time for a Socrative test is at the end of a teaching session. There are, of course, alternatives. For instance, a test on a given home reading could be carried out at the beginning of a session as a feature of the 'flipped classroom' approach.

My research on Socrative is distinctive in that it was with social, rather than natural science students, but the key findings are in line with those studies on Socrative use with engineering, physics, pharmacy, medical and IT students. The one statistical result worth reiterating is that my students thought Socrative tests are not simply light relief from a lecture, but a genuine learning aid. The qualitative responses show that students consider, as one might expect, a good educational means of breaking up a lecture. The matter of what form Socrative questions might take has not been discussed in the literature. My use of Socrative over the last three academic years was initially in the form of straight tests of knowledge after lectures. I have also come to use the device to introduce factual information in a question/answer format on a subject that otherwise would be dry and hard to digest. Finally, I have used it to elicit opinions on subjects on which students are unforthcoming. Socrative is therefore potentially more versatile and creative than simply an online testing medium. 
Sam Pryke is Senior Lecturer in Sociology at Wolverhampton University. He teaches modules on social theory, research methods, globalisation and migration. He is currently pursuing learning and teaching research on video feedback. Email: Sam.Pryke@wlv.ac.uk

\section{References}

Aslan, B. and H. Seker (2016), 'Interactive Response Systems (IRS) Socrative application sample', Journal of Education and Learning 6, no. 1: 167-174. https://doi.org/ 10.5539/jel.v6n1p167.

Awedh, M., A. Mueen, B. Zafar and U. Manzoor (2014), 'Using Socrative and smartphones for the support of collaborative learning', International Journal of Integrating Technology in Education 3, no. 4: 19-24. http://airccse.org/journal/ijite/papers/3414ijite02.pdf.

Badia, J. D., F. O. Cazevieille and J. M. N. Jover (2016), 'On-line quizzes to evaluate comprehension and integration skills', Journal of Technology and Science Education 6, no. 2: 75-90.

Balta, N. and K. Tzafilkou (2019), 'Using Socrative software for instant formative feedback in physics courses', Education and Information Technologies. 24, no. 1: 307-323. https://doi.org/10.1007/10639-018-9773-8.

Business Wire (2016), 'Socrative PRO: MasteryConnect Launches Premium Formative Assessment App’, 27 July, http://www.businesswire.com/news/home/20160727005240/ en/Socrative-PRO-MasteryConnect-Launches-Premium-Formative-Assessment.

Dervan, P. (2014), 'Increasing in-class student engagement using Socrative (an online student response system)', AISHE-J: The All Ireland Journal of Teaching and Learning in Higher Education 6, no. 3: 1801-1813. http://ojs.aishe.org/index.php/aishe-j/ article/view/180.

Guarascio, A. J., B. D. Nemecek and D. E. Zimmerman (2017), 'Evaluation of students' perceptions of the Socrative application versus a traditional student response system and its impact on classroom engagement', Currents in Pharmacy Teaching and Learning 9, no. 5: 808-812. https://doi.org/10.1016/j.cptl.2017.05.011.

Levine, L. J. and R. S. Edelstein (2009), 'Emotion and memory narrowing: A review and goal-relevance approach', Cognition and Emotion 23, no. 5: 833-875. https://doi.org/ 10.1080/02699930902738863.

Lim, W. N. (2017), 'Improving student engagement in higher education through mobile based interactive teaching model using Socrative', 2017 IEEE Global Engineering Education Conference (EDUCON): 404-412. https://doi.org/10.1109/ EDUCON.2017.7942879. 


\section{Sam Pryke}

Méndez, D. and J. Slisko (2013), 'Software Socrative and smartphones as tools for implementation of basic processes of active physics learning in classroom: An initial feasibility study with prospective teachers', European Journal of Physics Education 4, no. 2: 17-24. http://dergipark.gov.tr/download/article-file/62733.

Nouri, J. (2016), 'The flipped classroom: For active, effective and increased learning especially for low achievers', International Journal of Educational Technology in Higher Education 13, no. 33: 1-10. https://doi.org/10.1186/s41239-016-0032-z.

Rae, M. G. and D. O’Malley (2017), 'Using an online student response system, Socrative, to facilitate active learning of Physiology by first year graduate entry to medicine students: A feasibility study', Mede Publish 6, no. 1: 1-17. https://doi.org/10.15694/ mep.2017.000004.

Szpunar, K. K., Y. K. Novall and D. L. Schacter (2013), 'Interpolated memory tests reduce mind wandering and improve learning of online lectures', Proceedings of the National Academy of Sciences of the United States of America 110, no. 16: 6313-6317. https:// doi.org/10.1073/pnas.1221764110.

Roediger, H. L. and J. D. Karpicke (2006), 'Test-enhanced learning: taking memory tests improves long-term retention', Psychological Science 17, no. 2: 249-255. https://doi.org/ 10.1111/j.1467-9280.2006.01693.x.

Tretinjak, M. F., A. Bednjanec and M. Tretinjak (2015), 'Interactive teaching with Socrative', paper at 38th International Convention on Information and Communication Technology, Electronics and Microelectronics (MIPRO): 848-851. https://doi.org/ 10.1109/MIPRO.2015.7160391. 